\title{
Impacts of Construction Risk Attributes on Organizational Performance of Registered Construction Companies in Khyber Pakhtunkhwa, Pakistan
}

\author{
Muhammad Kashif Khan ${ }^{1 *}$, Muhammad Wasim Jan Khan ${ }^{2}$, Kaleem Ullah Jan Khan ${ }^{3}$, Muhammad Ishaq \\ $\mathrm{Khan}^{4}$, Muhammad Faheem Jan Khan ${ }^{5}$ and Abdul Salam Lodhi ${ }^{6}$
}

${ }^{1}$ CECOS University of IT and Emerging Sciences Peshawar, Khyber Pakhtunkbwa, Pakistan; ${ }^{2}$ Department of Management Sciences, University College of Zhob, BUITEMS, (BUITEMS Sub-Campus Zhob) Balochistan; ${ }^{3}$ Jilin University China; ${ }^{4} I q r a$ University Peshawar, Khyber Pakhtunkhwa, Pakistan; ${ }^{5}$ Balochistan University of IT, Engineering and Management Sciences, Balochistan Pakistan; ${ }^{6}$ University College of Zhob, BUITEMS, (BUITEMS Sub-Campus Zhob) Balochistan

\begin{abstract}
Billion dollars construction industry almost everywhere in the world is struggling with issues regarding well-organized risk management. Due to the fact that having complex nature and involvement of numerous parties, the chances of being more prone to the unseen risk factors causing extensive delays, over budgeting, and underrated quality are quite recurring. A broad extent of literature is available on risk identification, analysis, and mitigation through various methods and techniques. The purpose of this study is to address the need of risk management practices in the construction industry of Khyber Pakhtunkhwa (KPK), Pakistan. The research work carried out with the involvement of 150 Pakistan Engineering Council (PEC) registered construction companies not only emphasizes on the crucial risk factors associated with construction projects but also insights into the impacts of the risk factors on the organizational performances. The relationships between risk factors in the fields of Site Conditions, Resources, Project Parties, and Project Features and organizational performances including Profitability and Cost Risk Impact are developed through regression analysis using SPSS software. It is hoped that this research work will inform all concerned about risk management practices, possible risk factors, and their consequences upon organizational performances.
\end{abstract}

Received: January 10, 2020; Accepted: May 20,2020; Published: June 20, 2020

*Correspondence: Muhammad Kashif Khan, CECOS University, Peshawar, Pakistan; Email: engr.kashif.khan@outlook.com

Citation: Khan, M.K., M.W.J. Khan, K.U.J. Khan, M.I. Khan, M.F.J. Khan and A.S. Lodhi., 2020. Impacts of construction risk attributes on organizational performance of registered construction companies in Khyber Pakhtunkhwa, Pakistan. Journal of Engineering and Applied Sciences, 39(1): 47-56.

DOI: http://dx.doi.org/10.17582/journal.jeas/39.1.47.56

Keywords: Construction risk, Risk management, Risk analysis, Construction management

\section{Introduction}

$\mathrm{R}$ isk management practice is becoming a crucial need of time in construction industry in Pakistan to ensure the projects are completed within time, budget, to enhance quality and profitability and also to eradicate and minimize losses and undesirable consequences. Globally, risk management practice is necessary for carrying out successful construction projects. Similarly, Pakistan is a developing country therefore an efficient construction industry with minimum delays in construction projects can markedly enhance the chances of its economic prosperity and financial stability. Haseeb et al. (2011) narrated that if any construction project succeeds the specified time of completion or duration, on which all the involved parties agreed on will be termed as delay in construction. Smith (2009) identified that unique nature of construction projects in the context of complicated design and complex processes, financial 
problems, environmental conditions, political interference, nature of contract and built once make it highly vulnerable for the high degree of risk.

Banaitiene and Banaitis (2012) identified that risk management can be helpful for all involved parties like clients, suppliers, contractors, and consultants in accomplishing their goals and interests without negatively affecting the project objectives like, cost, time and quality. Szymanski (2017) stated that proper and adequate risk management system can markedly minimize risk from construction projects, though it is impossible to eliminate all the risks. Adeleke et al. (2018) narrated that without proper risk management system the project objectives will be affected negatively and will result in delays and increased costs in construction projects.

The practices carried out in construction projects in Pakistan regarding risk management are not practically enough to guarantee within time completion, under specified budget completion and proposed quality measures. Therefore, this research work tries to address the need of risk management practices in construction industry of KPK-Pakistan and to identify relationship among major risk factors and their consequences upon the organizational performances. Hence, the conceptual framework of this study consists of 4 independent variables as;

1. Site conditions

2. Resources

3. Project parties

4. Project features

And dependent variables (firm performances) as;

1. Profitability

2. Cost risk impact

\section{Literature review}

According to Chandra (2015) risk is the probability of an event which may result in opportunity or a threat on the project objectives such as specified budget, duration of the construction project, quality of the construction, financial aspects, and customer satisfaction. Main causes of the risk are requirement, constraint, assumption, and condition that create the probability of positive or negative outcome. Occurrence of one or more of these causes will result in risk and will have one or more impacts. Choudhry and Iqbal (2013) found that current discrepancies regarding risk management application and imple- mentation are the immaturity in its execution, lack of the risk management practices and its novel nature within construction industry. The parties involved in carrying out the construction project have no full understanding of the risk management sensitivity, its implementation and integrative mechanism thus ending up with undesirable circumstances. Pakistan is a developing country with low literacy rate so it is hard to adapt to the modern techniques, new technologies, lengthy and technical ways of documenting the risk by managers and contractors. Although risk management saves energy, time and cost but hiring a risk management expertise is too expensive that is why many organizations ignore the matter paving the ways for the routine delays, poor quality, cost overrun and less profitability (Azad, 2016).

Risks factors or attributers are definitely not limited to some aspects of construction projects, but can affect almost all sectors related to the project. Some of the most prone areas for the risk factors are discussed below.

\section{Site conditions}

Site conditions such as local soil and geotechnical conditions have caused changes in duration of strong ground motion, amplitude, and spectral content and hence resulted in the destruction of structures (Trifunac,2016).On the other hand, due to the climate changes heavy rainfalls are becoming more often and lead to the floods most of the times, which causes a severe damage to the human made infrastructure and environment. The floods in 2010, which devastated most parts of the Pakistan, were named by the Govt. of Punjab as super floods (Flood Report, 2011), came after the routine monsoon season with the flood level never seen or recorded before in the know history of Indus river system. The floods caused destruction on a very large scale devastating approximately 160,000 $\mathrm{km}^{2}$ of land or more clearly making 78 districts out of 141 submerged. It was in nowhere confusing to call it super floods that spread across KPK, Punjub and Sindh provinces of Pakistan, and accounted for the death tolls rising up to 2000 and the destruction in whole or partially of the homes in the area affected (Weekly Epidemiological Bulletin, 2010).

Due to the presence of dangerous materials and equipment on construction site, which includes even explosives in case of tunnel construction or rock excavation, highly inflammable chemicals, high 
voltages and volatiles which can anytime cause fires or expulsions. It becomes really difficult for engineers and workers to stay safe in most of the cases, so these must be properly arranged, and free roaming spaces must be there to ensure work force safety (Ning et al., 2018). In order to cope with the delays that would occur in winters, many United Kingdom construction companies race up their progresses in months of summer, now if these months are hit by hot weather conditions, eventually it will result in having an effect on the project progress, business survival and financial performance (Wedawatta et al., 2011). Hot weather surroundings can cause technical problems on site regarding construction for examples the American Concrete Institute (ACI, 2006) describes the hot weather conditions as, hot weather could be any combination of conditions which causes rapid moisture loss and increases the rate of hydration of the cement thus leading to unwanted consequences in concrete. Crissinger (2005) stated that rapid evaporation of moisture from concrete results in low compressive strength of concrete and make it weak and curled upward.

\section{Resources}

Project resources have numerous risk attributers related with the field itself. It can vary from risks associated with, quality of construction, availability of skilled labor, construction equipments, and everything that goes in that particular project as a resource. The tool which determines the way that activity should be performed during the proposed construction execution and estimates the after results of the performance of that particular activity is called design quality. On the other hand, construction process quality is the tool which directs the ways about activity control during the process of construction execution for the successful attainting of the required and described quality parameters. It is always the control which plays the part irrespective of design quality no matter how good that is (Oakland and Marosszeky, 2006). Not only quality machinery and materials add to the quality of construction, but construction management practices are necessary at the same time as well. In order to acquire these quality requirements in construction, first of all the customer requirements must be undertaken, then all steps to cope up with requirements of the customer must be thoroughly planned and in last the more important during construction phase all measures must be undertaken to execute and deliver in accordance with these requirements (Rumane, 2010).

\section{Project parties}

Disputes among the project parties are crucial and affect the project in many ways. Type of disputes according to the criteria of relative importance was ranked and it was concluded that disputes related to contractors are more frequent with highest relative importance value. The disputes because of contractors further cause in six different types of disputes to be termed as sub-disputes. Among the consequences of sub-disputes delays in construction is on top with highest relative value, followed by time extensions, financial collapse of the contractor, poor tendering process, and underrated quality of construction. When all the causes of sub-disputes evaluated and analyzed together, it can be concluded that problems regarding contracts have the highest relative importance value and hence is the major source of dispute in construction as well. The results stated that causes of disputes regarding human nature and project nature are not observed very often and are having the least relative importance values (Cakmak and Cakmak, 2014).

Another researchers Adeleke et al. (2018) noted a relationship between political influences and construction risk management, the nature of relationship turned out to be an insignificant. Also the Scupola (2003) found out the effect of economic factors on construction management, which according to him turns out to be positive most of the times. He further explained that competitive environment in economy and role of the ruling party have a pleasant effect on the construction risk management when construction appropriate materials are in limited supplies in the local market. In highly competitive economic market construction companies tend to achieve the competitive edge over the competitors, which make companies to be more innovative and creative in order to deal with the modern day requirements.

Another important drive which controls and affects the behaviors of the concerned parties working on the execution of construction projects is rules and regulations. Rules and regulations in construction projects can be termed as the statements, calibers, and relevant procedures to be adopted by organization that address the guidelines for the uses of materials in construction, all the procedures and activities which 
are involved before commencement of the project, and safety of the workers and crew (Simpkins, 2009). The risk in construction project is markedly reduced when all the set up rules and regulations by the government are thoroughly and widely followed in all aspects of project including acquiring construction materials, drawing plans, or any other activity related to construction (Gibb, 2011).

\section{Project features}

Corruption in construction industry was not of the interest of researcher for a long time, but during the late 90s, several corruption cases in the industry attracted the attentions of researchers to the matter. In modern times, among many individual researchers and analysts, government organizations, construction companies, and third parties have realized the matter of corruption in construction sector and are playing their role in eliminating the problem of corruption in order to carry the business in honest and transparent ways (Saenz and Brown, 2018). Other researchers De Jong et al. (2009) tried to estimate the amounts of corruption in figures, however according to them the exact cost of the corruption cannot be identified but approximately 10 percent of the total cost of a construction project goes into corruption. By this approximation this corruption amount can stand up to 500 billion USD annually throughout the globe. This figure really needs to be properly analyzed and attention must be given to this matter.

\section{Profitability}

It goes back to the Beaver (1966) and Altman (1968) when they approached with the models of company's failure in their literature. The concept of failure of construction project was released back in the 90s and attracted subsequent amount of researchers to the matter. In studying failure of construction companies, the set of techniques and set of selected variables that can be used for some companies do not stand valid for others as well. The variables often used in studying construction company failure contain four variables, categorically: liquidity ratios, leverage ratios, profitability ratios, and activity ratios. They all cover up for organizational performances only and mainly ( $\mathrm{Ng}$ et al., 2011). So many organizations tends to try to acquire projects when the construction industry have sufficient potential for work, in this case some organizations even go beyond their limits and go for projects which are too big to handle for them. This eventually results in the expenditure of the available cash and resources which can lead to the organization failure or hurting their reputation very badly. When construction industry is enjoying the fruitful times with construction works are easy and widely available, and profit margins are also good at the time this make the construction employees satisfied with wedges in industry. But once the construction workers enjoy the lavish period in the industry, it becomes hard and quite an unacceptable matter when the settle for low wedges than they were used to. It is further stated that, the recourses in the world would come to an end but not the desires of the people, and name this unwanted situation as 'scarcity' (Netscher, 2014).

\section{Cost risk impact}

Cost overrun often termed as increased cost or budget overrun is the amount that consists of unexpected and unknown extra costs that happened due to the underestimation of the real budget of any infrastructure project. In construction risk management it is one of the significant factors to study so that it can be avoided and maximum profitability and returns from infrastructure projects can be assured (Al-Hazim et al., 2017). In many developing countries like Afghanistan, where construction industry is a main factor and adds up to 10 percent to GDP annually. It also plays an imperative role in infrastructure and social development of the country. But still the construction industry has to encounter many challengers including cost overrun, customer dissatisfaction, and less productive nature (AISA, 2012).

By Mahamid and Bruland (2011) in another comprehensive study on the indicators that affect the project schedule and project cost in construction industry. He carried out a detailed survey in Palestine, containing 40 consultants to figure out the key factors that affect the project cost overrun. After the conduction of the survey, the consultants were of the opinion that because of higher fluctuations in the materials prices, project size, and complexities in design, projects suffer cost and time overruns. Apart from these findings it was found from the research study that budgets for 76 percent of projects is estimated over the required budget and for the remaining 24 percent projects it is under estimated, and the average difference in the actual and estimated cost was found to be 15 percent in the construction projects. 


\section{Materials and Methods}

\section{Research design}

The model developed for the research study, included site conditions, resources, project parties, and project features as independent variables and profitability and cost risk impact as dependent variables. This research model, after the necessary data input for each independent or dependent variable will be able to indicate quantitatively the impact of independent variables on one of the dependent variables.

Table 1: Research hypothesis.

\begin{tabular}{ll} 
Independent variable & $\begin{array}{l}\text { Hypothesized relationship with } \\
\text { organizational performances }\end{array}$ \\
\hline Site conditions & Significant \\
Resources & Significant \\
Project parties & Significant \\
Project features & Significant
\end{tabular}

A detailed questionnaire was prepared with the help of research performed by El-Karim et al. (2017) and with the guidance of expertise in the field. The questionnaire is based on Likert scale which allows respondent to response on a scale from 1-5, 1 being strong disagreement to the statement and 5 being strongly agreeing with the statement. The questionnaire comprises of two sections one about demographics, which collects information about respondent in the form of gender, marital status, age, qualification and years of experience. The second part of questionnaire is staged into six sections four for independent variables including site conditions, resources, project parties, and project features and two for dependent variables, including profitability and cost risk impact. The second part contains total of 73 statements about each and every possible risk factor of the respective variable.

\section{Data collection}

The research was carried on construction companies registered with Pakistan Engineering Council (PEC), operating in KPK. In order to have the possibility of happening of each and every risk factor selected for the research, construction companies doing projects up to worth 4000 million PKR, and beyond up to no limit were selected. Such type of construction companies are categorized by Pakistan Engineering Council under the sequence of $\mathrm{C} 2, \mathrm{C} 1, \mathrm{CB}$, and $\mathrm{CA}$, with C2 limited up to 1000 million PKR worth of projects, $\mathrm{C} 1$ can execute projects up to the worth of 2500 million PKR, CB up to 4000 million PKR, and $\mathrm{CA}$ falls under no limit of project worth. The advantage of selecting construction companies of the categories $\mathrm{C} 2$ and higher up to $\mathrm{CA}$ was a good feature for the research because the presence of expertise in such big companies also resulted in quality response for the research data. Questionnaire was sent to the 150 such companies for data collection both online and on post. In the period of around 50 days total of 133 responses were collected. Out of the received 133 responses, 3 were rejected due to no demographic information filled on that, 2 were rejected because were answered by internees, and 3 more were rejected because of incomplete information regarding core data. In the selected 125 responses fit for research, 73 was responded by professionals having experience more the 15 years and 15 responders have had experience between 11 to 15 years. Out of all 125 responders 17 were post-graduates and 108 were graduates.

\section{Analysis}

In the principal component factor analysis, no item was deleted because all values were found closer to 1 and above 0.5 , thus proving sample adequacy. Reliability test was run for each variable separately in the SPSS software, the values of Cronbach's alpha $(\alpha)$ obtained are given in Table 2 .

\section{Table 2: Cronbach's Alpha.}

\begin{tabular}{|llll} 
S. No. & Variable & No. of items & Cronbach's Alpha \\
\hline 1 & Site conditions & 11 & 0.718 \\
2 & Resources & 13 & 0.733 \\
3 & Project parties & 20 & 0.719 \\
4 & Project features & 12 & 0.775 \\
\hline 5 & Profitability & 7 & 0.846 \\
6 & Cost risk impact & 10 & 0.824 \\
\hline
\end{tabular}

Referring to the Table 2 it becomes clear that all values of ' $\alpha$ ' ranges between 0.718 to 0.846 for variables, which indicates very good reliability of the data and shows that internal consistency is present among the items of variables and data is ready for further analysis.

Whenever the relation includes independent variables and dependent variables, regression analysis is used as quantitative method of research during the analysis. Here in our case, the quantitative results for the research model are obtained. 
In linear regression model, it is important for all independent variables that they should not have correlated impact in between. In this case the prediction of the effect on the dependent variable can't be identified purely. Multicollinearity is the condition when more than two independent variables are sharing the same variance in the dependent variable. When such case happens the less significant statistics in result are expected. Both collinearity and multicollinearity are measured in variance inflation factor (VIF), which in numerical values goes from 1 to 20 , and 1 to 10 respectively in each case. 1 or nearer to it means no collinearity or multicollinearity and vice versa. Tolerance values of 0.10 are considered satisfactory.

Multicollinearity results for all predictor variables are as follow:

When the independent variable, 'Site Conditions' was checked against the remaining three independent variables, resources, project parties, and project features for multicollinearity, the following variance inflation factors values was found for against each another independent variable.

Table 3: Collinearity statistics for site conditions.

\begin{tabular}{llll} 
Model & \multicolumn{2}{c}{ Collinearity statistics } \\
& & Tolerance & VIF \\
\hline 1 & Project features & 0.190 & 5.256 \\
& Project parties & 0.191 & 5.237 \\
& Resources & 0.991 & 1.009
\end{tabular}

From Table 3, variance inflation factors are less than 10 and tolerance values are above 0.10 , in case of site conditions multicollinearity check against other three independent variables, which is satisfactory.

Table 4: Collinearity statistics for resources.

\begin{tabular}{|c|c|c|c|}
\hline \multirow{2}{*}{\multicolumn{2}{|c|}{ Model }} & \multicolumn{2}{|c|}{ Collinearity statistics } \\
\hline & & Tolerance & VIF \\
\hline \multirow[t]{3}{*}{1} & Site conditions & 0.995 & 1.005 \\
\hline & Project features & 0.191 & 5.236 \\
\hline & Project parties & 0.191 & 5.224 \\
\hline
\end{tabular}

From Table 4 it is clear that all VIF values are well below the limit of 10 , and also all values of Tolerance are above 0.10 so it can be said that there is no multicollinearity present between independent variable, Resources and other three independent variables.
Table 5: Collinearity statistics for project parties.

\begin{tabular}{llll} 
Model & \multicolumn{2}{c}{ Collinearity statistics } \\
& & Tolerance & VIF \\
1 & Site conditions & 0.959 & 1.042 \\
& Resources & 0.958 & 1.044 \\
& Project features & 0.993 & 1.007
\end{tabular}

Again all the values of VIF are nearer to one with Tolerance values above 0.10 from Table 5 which indicated that there is almost no multicollinearity present between project parties and the remaining three independent variables.

From the Table 6 again it is obvious that no multicollinearity exists between project features and other independent variables as the values of VIF are very closer to one and all values of Tolerance are above 0.10 .

Table 6: Collinearity statistics for project features.

\begin{tabular}{llll} 
Model & \multicolumn{2}{c}{ Collinearity statistics } \\
& Tolerance & VIF \\
1 Site condtions & 0.961 & 1.041 \\
& Reso urces & 0.961 & 1.041 \\
& Project parties & 0.998 & 1.002
\end{tabular}

From all the checks and tests, it is now clear that the data used for further analysis will be okay and will result in significant results during the linear regression of the research model for predictor and dependent variables.

In the final stage of analysis which is quantitatively checking the effect of predictor variables on the dependent variables, of the research model. For this purpose, the effect of predictor variables which are site conditions, resources, project parties, and project features on dependent variable, Profitability was checked in first place. After performing the necessary steps in SPSS software on the research data the results obtained are shown in Table 7.

Significant impact of predictor variables on dependent variable, Cost Risk Impact is shown in Table 8.

Before going into the details of analysis, in the Tables 7 and 8 ' $d f$ ' accounts for degree of freedom related with source of variance, F-value is mean square regression divided by mean square residual and $\mathrm{p}$-value associated with $\mathrm{F}$-value, when is less than 0.05 approaching 0.00 indicates independent 
Table 7: Relationship of risk factors with profitability.

\section{Model summary}

\section{Model}

1

ANOVA

$\begin{array}{llll}\text { Model } & \begin{array}{l}\text { Sum of } \\ \text { Squares }\end{array} & \text { df } & \text { Mean Square } \\ \text { Regression } & 19.378 & 4 & 4.845 \\ \text { Residual } & 33.887 & 120 & 0.282 \\ \text { Total } & 53.265 & 124 & \end{array}$

Coefficients

\begin{tabular}{llllll} 
Model & \multicolumn{2}{l}{ Unstandardized Coefficients } & Standardized coefficients & $\mathbf{t}$ & Sig. \\
& B & Std. Error & Beta & & \\
1 (constant) & 0.975 & 0.495 & & 1.970 & 0.051 \\
Site conditions & 0.076 & 0.089 & 0.063 & 0.852 & 0.396 \\
Resources & 0.053 & 0.105 & 0.038 & 0.504 & 0.615 \\
Project parties & -1.319 & 0.227 & -0.967 & -5.799 & 0.000 \\
Project features & 1.696 & 0.221 & 1.280 & 7.660 & 0.000
\end{tabular}

Table 8: Relationship of risk factors with cost risk impact.

\section{Model summary}

$\begin{array}{lllll}\text { Model } & \mathbf{R} & \mathbf{R}^{2} & \text { Adjusted } \mathbf{R}^{2} & \text { Std. Error of Estimate } \\ 1 & 0.628 & 0.394 & 0.374 & 0.446\end{array}$

ANOVA

$\begin{array}{llllll}\text { Model } & \text { Sum of Squares } & \text { df } & \text { Mean square } & \text { F } & \text { Sig. } \\ \text { Regression } & 15.534 & 4 & 3.884 & 19.501 & 0.000 \\ \text { Residual } & 23.898 & 120 & 0.199 & & \\ \text { Total } & 39.432 & 124 & & & \end{array}$

\section{Coefficients}

Model

1 (constant)

Site conditions

Resources

Project parties

Project features

\section{Unstandardized Coefficients}

B

0.977

0.013

0.007

$-0.751$

1.294
Std. Error

0.416

0.075

0.088

0.191

0.186
Standardized Coefficients $\mathbf{t}$

Beta

$\begin{array}{lll} & 2.349 & 0.020 \\ 0.012 & 0.171 & 0.865 \\ 0.006 & 0.080 & 0.936 \\ -0.640 & -3.933 & 0.000 \\ 1.135 & 6.960 & 0.000\end{array}$

variable is predicting dependent variable. 'B' are used for predicting dependent variable, paired up with ' $t$ ' values, for example in Table 7, in independent variable 'project features' 1.696 (B-value) times change in magnitude in it will have an impact 7.660 ( $t$-value) times in dependent variable, Profitability. Standardized coefficients are called 'Beta'.

\section{Conclusions and Recommendations}

From the Table 7, the $\mathrm{R}^{2}$ value for the model is 0.364 , $F$ value is 17.156 , and from coefficients section, by looking at the values of ' $\mathrm{B}$ ' which is 0.076 in this case, ' $t$ ' value is 0.852 , and at the same time ' $p$ ' value is 0.396 . From all these information it can be finally derived that the independent variable site conditions have direct relationship with the dependent variable Profitability in this case, but 'p' value of 0.396 indicates that it is well above the limit of 0.05 so the impact will not be that considerable. For relationship between resources and profitability, ' $\mathrm{B}$ ' is 0.053 and ' $\mathrm{t}$ ' value is 0.504 which indicates a positive relation, but ' $\mathrm{p}$ ' value of 0.615 makes it insignificant.

For finding out relationship between project parties and profitability, by looking at the ' $\mathrm{B}$ ' value which is -1.319 and ' $t$ ' value of -5.799 indicates relationship between project parties and profitability is negative June 2020 | Volume 39 | Issue 1 | Page 53 
which means that with decrease in risk factors associated with project parties, profitability will increase significantly and vice versa. Value of 'p' which is 0.000 indicates that the relationship is significant as well. It is a matter of fact that most of the construction companies end up in less profits here in KPK it is probably because minimum efforts are taken regarding risk management. Risk attributes elaborated in this research work in the field of project parties include type of owner, construction management practices, organizational makeup, eased environment for work, communicating changes, team experience, ambiguity in engineering design, complexity in design, errors in the design, pre-qualification of contractor, contractor reluctance in adopting new technologies, contractor always performs (as per design), often reworks, subcontracting, contractor reputation, contractor performing multiple projects, project management principles, definition of project scope, quality control procedures, and contracting style. Minimum risk levels in the above mentioned risk attributes can lead to higher profitability.

For the relationship of profitability and project features, from the values of ' $\mathrm{B}$ ' equals to 1.696 , ' $\mathrm{t}$ ' is 7.660 and ' $p$ ' value of 0.000 , it can be found that the relationship is positive and significant. Higher control over risk factors associated with project features will cause a significant increase in profitability and vice versa. The risk factors associated with project parties include availability of variations, delays in release of funds, fluctuations in prices, changes in currency rates, company financial status, interest rate, magnitude of project, corruption and frauds, project in remote areas, alterations in set of laws, first track schedule, and project time period. Again it is a validation of the fact that most of the construction companies in KPK have very little countermeasures for the above mentioned risk attributes which as a result cause in little profits for the company.

From the Table 8, the $\mathrm{R}^{2}$ value for the model is 0.394 , the ' $\mathrm{F}$ ' value is 19.501 and from coefficients section, for the relationship between predictor site conditions and dependent variable cost risk impact, the values of 'B', 't, and 'p' are $0.013,0.171$, and 0.865 , respectively. These figures indicated that relationship is positive but not significant as value of ' $p$ ' is beyond its upper limit. From the same table, for resources and cost risk impact relationship, 'B', 't, and 'p' values are 0.007 , 0.080 , and 0.936 , respectively, which again shows that the relation is positive but not significant.

For the relationship between project parties a predictor variable and cost risk impact a dependent variable, the values of 'B', ' $t$ ', and 'p' are $-0.751,-3.933$, and 0.000 respectively. It shows that the relationship is negative and significant as well meaning that effective control over risk factors associated with project parties will significantly reduce the risk of cost overrun and vice versa. Again in the context of KPK, many construction companies often ignore the need of risk management in projects especially in the risk attributes related to Project Parties which causes the companies to bear cost overruns.

For the relationship between cost risk impact and project features, the values of 'B', ' $t$ ', and 'p' are 1.294, 6.960, and 0.000 . This relation tends to be positive and indicates that higher the probability of occurrences of risk factors in project features will markedly increase the chances of cost overrun. Risk attributes in the field of project features mentioned earlier should be properly mitigated and assessed so that cost overruns in the construction industry of KPK could be prevented.

\section{Results of research hypothesis.}

\section{S.No. Statement of hypothesis}

Result

1

'Site Conditions' has significant relation- unsupported ship with organizational performances.

2 'Resources' has significant relationship with organizational performances.

3 'Project Parties' has significant relationship with organizational performances.

unsupported

supported

'Project features' has significant relation- supported ship with organizational performances.

There is always a room for improvement, innovation and addition to the existing body of knowledge regarding risk management in construction industry. It is hoped that the research work conveys the idea of its existence and can benefit the concerned officials, students or any other individual related to the field of construction. Risk management in construction industry is wide open for further research by undertaking modern day challenges. The research model used in this research can also be made broad by the addition of extra predictor variables which can have their impact on the organizational performances and the same goes for organizational performances or dependent variables. As discussed the research 
was carried out in the KPK-Pakistan so it can be replicated for any other location within or out the country with the addition and modification of the research parameters and criterion according to the conditions of the respective locality.

\section{Novelty Statement}

Very few researchers have just tried to highlight the various risk factors in construction industry of Khyber Pakhtunkhwa, Pakistan. On the other hand, the uniqueness of this research work is that, it directly aims at elaborating various significant risk attributes and also the performance of construction organizations when such risk attributes are likely to be present.

\section{Author's Contribution}

Muhammad Kashif Khan: Main idea, model preparation, questionnaire preparation, analysis, literature review, writing and formatting.

Muhammad Wasim Jan Khan: Assisted in finalizing research model, finalizing questionnaire, analysis checks and selection of construction companies to be surveyed.

Kaleem Ullah Jan Khan: Assisted in methodology, analysis and proof reading.

Muhammad Ishaq Khan: Assisted in literature review, questionnaire survey, data collection and its authentication.

Muhammad Faheem Jan Khan: Assisted in questionnaire survey and proof reading.

Abdul Salam Lodhi: Idea discussion, proof reading

\section{Conflict of interest}

The authors have declared no conflict of interest.

\section{References}

Adeleke,A.Q.,A.Y.Bahaudin,A.M.Kamaruddeen, J.A. Bamgbade, M.G. Salimon, M.W.A. Khan and S. Sorooshian. 2018. The influence of organizational external factors on construction risk management among Nigerian construction companies. Saf. Health Work, 9: 115-124. https://doi.org/10.1016/j.shaw.2017.05.004

Afghanistan Investment Support Agency, (AISA). 2012. Annual report of afghanistan investment support agency. Kabul: AISA; 2012.

Al-Hazim, N., Z. Abu Salem and H. Ahmad. 2017.
Delay and cost overrun in infrastructure projects in jordan. Proc. Eng., 182: 18-24. https://doi. org/10.1016/j.proeng.2017.03.105

Altman, E.I., 1968. Financial ratios, discriminant analysis and the prediction of corporate bankruptcy. J. Finance, 23(4): 589-609. https:// doi.org/10.1111/j.1540-6261.1968.tb00843.x

American Concrete Institute, 2006. Specification for hot weather concreting: ACI 305.1-06.

Azad, S., 2016. Risk analysis for Construction Projects in Pakistan. Int.J. Eng. Innov. Technol., Volume 5.

Banaitiene, N. and N. Banaitis. 2012. Risk management in construction projects. Risk management current issues and challenges. Chapter 19. https://doi.org/10.5772/51460

Beaver, W.H., 1966. Financial ratios as predictors of failure. J. Account. Res., 4: 71-111. https:// doi.org/10.2307/2490171

Cakmak, E. and P.I. Cakmak. 2014. An analysis of causes of disputes in the construction industry using analytical network process. Proc. Soc. Behav. Sci., 109: 183-187. https://doi. org/10.1016/j.sbspro.2013.12.441

Chandra, H.P., 2015. Structral equation model for investigating risk factors affecting project success in Surabaya. Proc. Eng., 125: 53-59. https://doi.org/10.1016/j.proeng.2015.11.009

Choudhry, R.M. and K. Iqbal. 2013. Identification of risk management system in construction industry in Pakistan. J. Manage. Eng., 21(1): 42-49. https://doi.org/10.1061/(ASCE) ME.1943-5479.0000122

Crissinger, J., 2005. Design and Construction vs Weather. Online Available at: https://www. scribd.com/document/211146784/2005-02crissinger (Accessed on: 10 January, 2021).

De-Jong, M., W.P. Henry and N. Stansbury. 2009. Eliminating corruption in our engineering. Leadership Manage. Eng., 9(3). https://doi.org/10.1061/(ASCE)15326748(2009)9:3(105)

El-Karim, M.S.B.A.A., O.A.M. Nawawy and A.M. Abdel-Alim. 2017. Identification and assessment of risk factors affecting construction projects. HBRC J. 13: 202-216. https://doi. org/10.1016/j.hbrcj.2015.05.001

Flood, 2010. The event, issues and way forward. Int. Works. Floods Pakistan, 2010 and 2011. Paper No. 272.

Gibb,K.,2011.Delivering new affordable housing in 
the age of austerity: Housing policy in Scotland. Int. J. Housing Market. Anal., 44: 357-368. https://doi.org/10.1108/17538271111172157

Haseeb, M., X. Lu, A. Bibi, M. Dyian and W. Rabbani. 2011. Problems of projects and effects of delays in the construction industry of Pakistan. Aust. J. Bus. Manage. Res., 1(5): 41-50.

Mahamid, I., and A. Burland. 2011. Cost overrun causes in infrastructure projects, consultants perspective. $2^{\text {nd }}$ Int. Conf. Const. Project Manage., IPEDR15.

Ministry of Health, 2010. Government of Pakistan, World Health Organization, weekly epidemiological bulletin: Flood response in Pakistan: 1(1): 1-4.

Netscher, P., 2014. Building a successful construction company: The practical guide. Subiaco: Panet Publications.

Ng, S.T., J.M. Wong and J. Zhang. 2011. Applying $z$-score model to distinguishinsolvent construction companies in China. Habitat Int., 35(4): 599-607. https://doi.org/10.1016/j. habitatint.2011.03.008

Ning, X., J. Qi and C. Wu. 2018. A quantitative safety risk assessment model for construction site layout planning. Saf. Sci., 104: 246-259. https://doi.org/10.1016/j.ssci.2018.01.016

Oakland, J.S. and M. Marosszeky. 2006. Total quality in the construction supply chain. Butterworth-Heinemann, England. https:// doi.org/10.4324/9780080455280
Rumane, A.R., 2010. Quality management in construction projects, CRC Press, U.S.A.

Saenz, C. and H. Brown. 2018. The disclosure of anticorruption aspects in companies of the construction sector: Main companies worldwide and in Latin America. J. Cleaner Prod., 196: 259-272. https://doi.org/10.1016/j. jclepro.2018.06.045

Scupola, A., 2003. The adoption of Internet commerce by SMEs in the south of Italy: An environmental,technological and organizational perspective. J. Glob. Inf. Technol. Manage., 61: 52-71. https://doi.org/10.1080/109719 8X.2003.10856343

Simpkins, R.A., 2009. How great leaders avoid disaster: the value of contingency planning. Bus. Strategy Ser., 102: 104-108. https://doi. org/10.1108/17515630910942241

Smith, N.J., 2009. Managing risks in construction projects. Blackwell Science Ltd. London.

Szymanski, P., 2017. Risk management in construction projects. Proc. Eng., 208: 174-182. https://doi.org/10.1016/j.proeng.2017.11.036

Trifunac, M.D., 2016. Site conditions and earthquake ground motion. A review. Soil Dyn. Earthq. Eng., 90: 88-100. https://doi. org/10.1016/j.soildyn.2016.08.003

Wedawatta, G., B. Ingirige, K. Jones and D. Proverbs. 2011. Extreme weather events and construction in SMEs: Vulnerability, impacts, and responses. Struct. Surv., 29: 106-119. https://doi.org/10.1108/02630801111132795 